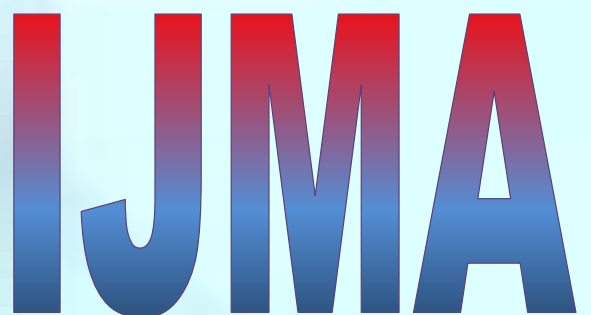

INTERNATIONAL

Journal of MEdical

\section{ARTS}

Volume 3, Issue 1 (Winter 2021)

http://ijma.journals.ekb.eg/

Print ISSN: 2636-4174

Online ISSN: 2682-3780

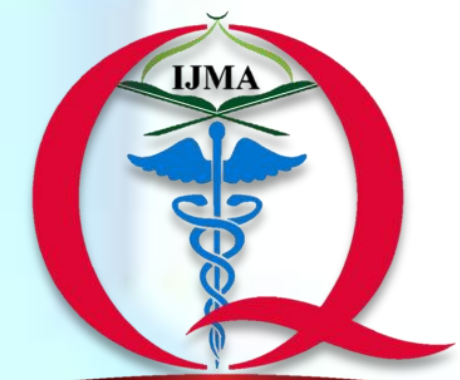

International Jounnal of Medical Arts

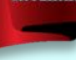




\section{About IJMA}

- International Journal of Medical Arts is the Official Journal of the Damietta Faculty of Medicine, Al-Azhar University, Egypt

- The First Issue was published in July 2019

- It is an International, Open Access, Double-blind, Peerreviewed Journal

- Published four times a year

- Published under the following license: Creative Commons Attribution-ShareAlike 4.0 International Public License (CC BY-SA 4.0). It had updated from the Creative Commons license [CC BY] in volume 2, Issue 4, October 2020

- The Egyptian Knowledge Bank hosts the web site of IJMA

- The Egyptian Knowledge Bank supports IJMA

- IJMA is indexed in the "Directory of Open Access Journals" Indexed on 15 January 2021.

- IJMA follows the regulations of the International Committee of Medical Journal Editors (list date 1/21/20)

- IJMA is a member of The International Society of Managing and Technical Editors

- IJMA is listed in Index Copernicus

- IJMA is listed in Publons, as EKB is an official partner with Clarivate Analytics
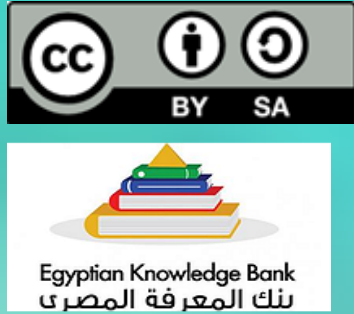

\section{DOAJ}

CMNE

ISMTE

INDEX COPERNICUS

publons 
International Journal of Medical Arts 2021; 3 [1]: 1060-1068.

Available online at Journal Website
https://ijma.journals.ekb.eg/
Main subject [Urology]*

Original article

\title{
Percutaneous Nephrolithotomy in the Modified Flank Free Supine Position: An Observational Prospective Study to Identify the Surgeon's Learning Curve
}

Ahmed M. Abdel Gawad; Ahmed Yousef Aboelsaad

Department of Urology, Damietta Faculty of Medicine, Al-Azhar University, Egypt[1].

\author{
Corresponding author: Ahmed M. Abdel Gawad \\ Email: aa.urology@domazhermedicine.edu.eg
}

Received at: August 16, 2020; Revised at: November 02, 2020; Accepted at: November 09, 2020

DOI: $10.21608 / / J M A .2020 .39468 .1156$

\section{ABSTRACT}

Background: Percutaneous nephrolithotomy was usually practiced in prone position. However, there is a recent shift towards supine position. This shift needs a continuous practice to increase the surgeon's learning curve.

Aims: To give an insight into the learning curve of a single surgeon, capable of doing percutaneous nephrolithotomy in the conventional prone position, during his transition to the supine one using different indicators.

Materials and Methods: This study included 80 procedures, equally divided into 4 groups and the following endpoints were recorded and compared among groups: operation and fluoroscopic screening times, volume of the irrigant fluid consumed, postoperative length of hospital stay, stone clearance rate and procedure related morbidity.

Results: The mean operation and fluoroscope screening durations showed a statistically significant decline with time. The operative time drop from 117 minutes at the beginning to about the half [60 minutes] after sixth months and working with 80 patients. The fluoroscopy time declined from 3.5 minutes at the beginning to 1.5 minute at the end. Our stone clearance rate continued to improve among groups [with advancement of learning curve] $[P=$ 0.034] without approaching the plateau. Also for other indicators [volume of the irrigant fluid consumed, postoperative length of hospital stay and complications], all showed statistical significant reduction with increased learning curve $[\mathrm{P}<0.0001]$.

Conclusions: Operative time and stone clearance rate continued improvement with increasing learning curve. However, the volume of irrigation fluid, rate and grade of complications and length of postoperative stay reached its plateau after 40 procedures.

Keywords:Conventional Prone Position; Learning Curve; Modified Flank Free Supine Position; Percutaneous Nephrolithotomy; Urinary Stones.

This is an open access article registered under the Creative Commons, ShareAlike 4.0 International license [CC BY-SA 4.0] [https://creativecommons.org/licenses/by-sa/4.0/legalcode.

Please cite this article: Abdel Gawad AM, Aboelsaad AY. Percutaneous Nephrolithotomy in the Modified Flank Free Supine Position: An Observational Prospective Study to Identify the Surgeon's Learning Curve IJMA 2021; 3[1]: 1060-1068. DOI: 10.21608/IJMA.2020.39468.1156

* Main subject and any subcategories have been classified according to the research topic. 


\section{INTRODUCTION}

Percutaneous Nephrolithotomy [PCNL] was first reported in 1976 by Fernström and Johansson ${ }^{[1][1]}$. Since then, it remains as a fascinating and powerful procedure always available for the treatment of large upper urinary tract stones. PCNL was first performed in the classical prone position that was generally adopted as the standard technique[2]2]. However, the conventional prone position has some drawbacks that derived urologists to look for alternative positions[3][3]. Many positions and modifications were proposed, including the supine position[4][4].

Although the first description of supine PCNL was published almost 30 years ago[5][5], its popularity has been gained in over the past 10-15 years when its benefits become more and more apparent[6]. Supine PCNL was first included in European Association of Urology [EAU] guidelines in 2012[7]. Before embarking on a new surgical technique, it is fundamental to define its "learning curve," that is, to determine the mean number of procedures an inexperienced surgeon needs to perform to be proficient in performing this kind of surgery competently[8][8]. To the best of our knowledge, only a handful of studies have been published aiming to evaluate the learning curve for PCNL. In these studies, many variables were used as markers to assess surgical competence. These variables included outcome measures (the stonefree rate ${ }^{[9]}$ and complication rate $)^{[9]}$ and treatment variables (the duration of surgery and

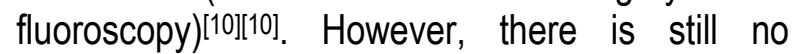
consensus regarding the best practical clinical surrogate markers of performance in PCNL operations ${ }^{[11] .}$

\section{AIM OF THE WORK}

The aim of this study is to determine the learning curve of a single surgeon, competent in doing PCNL in the conventional prone position, when shifted to the supine one, particularly the modified flank free using the following clinical endpoints: economic efficiency (operation and fluoroscopic screening times, the volume of the irrigant fluid consumed and postoperative length of hospital stay), effectiveness (stone clearance rate), and Procedure-Related Morbidity (reduction in hemoglobin concentration, blood transfusion, and complication rates), as indicators of performance.

\section{PATIENTS AND METHODS}

The present study is a prospective one. It included 80 consecutive PCNL procedures, randomly clustered over the period between March and November 2019. Informed consent has been obtained from all participants before the operation, and the protocol for this research project has been approved by our institutional review board [IRB: 0001236719-10-10].

Exclusion criteria included: Children $(<18$ years); Patients with renal anomalies (congenital or acquired) or skeletal abnormalities that might interfere with proper patient positioning, and; Patients with uncorrectable coagulopathies or severe associated co-morbid condition. The basic preoperative workups included: full history, clinical examination, biochemical and hematologic profiles, including urine cultures.

The presence of the stone and its characteristics (side, site, number, size, and complexity) were evaluated with a plain abdominal radiography (KUB film), gray-scale abdominopelvic Ultra-Sound Scan (USS), excretory intravenous urography (IVU), and non-contrast abdominopelvic spiral computed tomography scan (NCCT). The size of stones was determined by using their largest and smallest diameter. In cases with multiple stones, the sum of the largest and smallest diameter of each stone was used. In order to calculate the surface area (SA) of the stone, the following equation formulated by Tiselius and Andersson [12] [12] was used, where $L$ is length (the largest diameter), and $w$ corresponds to width (the smallest diameter): (SA = LWTO.25). For stone complexity grading, the "Guy's stone score" was used [13].

Antibiotics were given for at least five days before surgery based on the antibiogram results, and anesthetic risk assessment according to the American Society of Anesthesiologists (ASA) was performed the night of surgery.

All procedures were performed under general anesthesia by a single surgeon proctored by a senior fellow in the modified flank free supine position. With the patient in the dorsal lithotomy position, a 6- Fr open tipped ureteric catheter was 
inserted in the ipsilateral ureter. Then, two saline bags were placed, one under the ipsilateral chest and another under the buttocks, thus the patient is tilted to $\sim 20^{\circ}$. The flank at the surgery site was brought to the edge of the operating table away from the radiopaque part to avoid overlapping. The ipsilateral leg was placed straight with a cushion under the knee to avoid stretch. The contralateral leg was placed in an abducted and flexed position over the table. Percutaneous access was achieved under fluoroscopic (C-arm) guidance using an 18gauge needle. The puncture site was just below the lateral end of the $12^{\text {th }}$ rib and slightly medial to the posterior axillary line. Tract dilatation was accomplished using the Amplatz system dilators. The tract was dilated to $30 \mathrm{Fr}$ before placement of an Amplatz sheath in the collecting system. Fragmentation and stone removal were accomplished in all patients with Pneumatic lithoclast and stone grasping forceps through standard 26 Fr rigid nephroscope. Stone clearance was determined by a combination of fluoroscopy and rigid nephroscope at the end of the procedure. The operations were completed when residual fragments were not detected on fluoroscopic imaging and rigid nephroscopic control [26-Fr Karl Storz rigid Nephroscope]. Additional tracts were established when necessary, using the same access technique, according to the stone burden and calyceal anatomy with the aim of maximum stone clearance. After completion, the Amplatz sheath was withdrawn out of the collecting system after insertion of a nephrostomy tube through which an antegrade nephrography was done to ensure no extravasation and no colonic injury. The ureteric catheter was replaced by $\mathrm{JJ}$ ureteric stent if there were retained calculi and/or extravasation on nephrography.

Two-Hour post-operative, complete blood count [CBC] was sampled, and on the first post-operative day, all the patients had $\mathrm{CBC}$, serum creatinine [S.Cr.], and radiologic evaluation for residual stones by KUB film and USS. PCNL was considered successful if the kidney was completely free of stones or intrarenal residual fragments were smaller than $5 \mathrm{~mm}$ (CIRF; Clinically Insignificant Residual Fragment). Any detectable residual stones $\geq 5 \mathrm{~mm}$ were considered significant.
The 80 procedures were divided, based on their chronological order, into 4 groups, 20 procedures each. In order to determine the learning curve, the following outcome measures were recorded and compared among the groups: economic efficiency (operation and fluoroscopic screening times, the volume of the irrigant fluid consumed and postoperative length of hospital stay), effectiveness (stone clearance rate), and Procedure-Related Morbidity (reduction in hemoglobin concentration, blood transfusion, and complication rates). Complications were graded according to the modified Clavien system[14,15] [14], [15].

At the end of the study, data were collected and statistically analyzed using appropriate statistical tests and analytic programs (statistical package for social science SPSS) software, version 18 [IBM ${ }^{\circledR}$ SPSS $®$, Inc., Chicago, USA]. Data presented as the arithmetic mean, standard deviation, frequencies, and percentage for quantitative and qualitative data as appropriate. Statistical significance was considered with the two-sided $P$ value of less than 0.05 . Repeated one-way analysis of variance was calculated to track changes over time.

\section{RESULTS}

The patients' demographic data and the characteristics of the treated stones in each group are detailed in table 1. The operation time was derived from the anesthesia chart and defined as the time elapsed in minutes from the induction of anesthesia till the insertion of the nephrostomy tube. The operation time decreased from the mean of 117.1 minutes for the first 20 procedures to 91.9 minutes for the next $20 \mathrm{~s}$, and thereafter, further decreased to 79.4 minutes for the $41^{\text {st }}$ to $60^{\text {th }}$ to reach 60.5 minutes for the last group. This pattern of decline was statistically significant $(P<0.0001)$ (Figure 1).

Regarding the volume of the irrigant fluid consumed, as depicted in figure 2 , it declined from 30.5 liters for the first group to 14.5 liters for the second group to reach 9.85 liters in the third one. Afterward, a little fluctuation was observed for the fourth group. This pattern was also statistically significant $(P<0.0001)$. Considering fluoroscopy time and mean a drop in hemoglobin, as shown in 
figure 3 , both were markedly decreased with an increased learning curve $(P<0.0001)$. As regards the stone clearance rate, as shown in figure 4 , it continued to increase progressively from the first to the fourth 20 cases $(P=0.034)$, without reaching a plateau. Also, for the postoperative length of hospital stay, complications, and blood transfusion rates, as presented in table 2 , all showed a significant decrease with an increased learning curve $(P<0.0001)$.

Table [1]: Patients' Demographic and Stone Characteristics

\begin{tabular}{|c|c|c|c|c|c|c|c|}
\hline \multicolumn{2}{|l|}{ Variable } & First 20 & Second 20 & Third 20 & Fourth 20 & $\mathrm{~F}$ & $P$ \\
\hline \multicolumn{2}{|l|}{ Age } & $46.9 \pm 9.8$ & $44.9 \pm 10.4$ & $48.4 \pm 8.8$ & $44.65 \pm 8.07$ & 0.71 & 0.548 \\
\hline \multirow[t]{2}{*}{ Sex } & Male & $12[60.0 \%]$ & $14[70.0 \%]$ & $9[45.0 \%]$ & $10[50.0 \%]$ & \multirow[t]{2}{*}{2.99} & \multirow[t]{2}{*}{0.39} \\
\hline & Female & $8[40.0 \%]$ & $6[30.0 \%]$ & $11[55.0 \%]$ & $10[50.0 \%]$ & & \\
\hline \multicolumn{2}{|l|}{ BMl† } & $30.3 \pm 8.5$ & $28.8 \pm 6.1$ & $32.5 \pm 6.2$ & $30.8 \pm 5.1$ & 1.06 & 0.36 \\
\hline \multirow[t]{2}{*}{ Previous kidney surgery } & Yes & $6[30.0 \%]$ & $4[20.0 \%]$ & $2[10.0 \%]$ & $4[20.0 \%]$ & \multirow[t]{2}{*}{2.50} & \multirow[t]{2}{*}{0.47} \\
\hline & No & $14[70.0 \%]$ & $16[80.0 \%]$ & $18[90.0 \%]$ & $16[80.0 \%]$ & & \\
\hline \multirow[t]{2}{*}{ Stone side } & Right & $14[70.0 \%]$ & $9[45.0 \%]$ & $10[50.0 \%]$ & $13[65.0 \%]$ & \multirow[t]{2}{*}{3.47} & \multirow[t]{2}{*}{0.32} \\
\hline & Left & $6[30.0 \%]$ & $11[55.0 \%]$ & $10[50.0 \%]$ & $7[35.0 \%]$ & & \\
\hline \multirow[t]{2}{*}{ Stone multiplicity } & Multiple & $11[55.0 \%]$ & $8[40.0 \%]$ & $9[45.0 \%]$ & $5[25.0 \%]$ & \multirow[t]{2}{*}{3.86} & \multirow[t]{2}{*}{0.27} \\
\hline & Single & $9[45.0 \%]$ & $12[60.0 \%]$ & $11[55.0 \%]$ & $15[75.0 \%]$ & & \\
\hline \multirow{4}{*}{$\begin{array}{l}\text { Grading of Stone } \\
\text { Complexity }\end{array}$} & Grade I & $4[20.0 \%]$ & $6[30.0 \%]$ & $1[5.0 \%]$ & $14[70.0 \%]$ & \multirow[t]{4}{*}{45.19} & \multirow[t]{4}{*}{$<0.001^{*}$} \\
\hline & Grade II & $0[0.0 \%]$ & $10[50.0 \%]$ & $9[45.0 \%]$ & $6[30.0 \%]$ & & \\
\hline & Grade III & $12[60.0 \%]$ & $4[20.0 \%]$ & $7[35.0 \%]$ & $0[0.0 \%]$ & & \\
\hline & Grade IV & $4[20.0 \%]$ & $0[0.0 \%]$ & $3[15.0 \%]$ & $0[0.0 \%]$ & & \\
\hline \multirow[t]{2}{*}{ Radio-opacity } & Lucent & $9[45.0 \%]$ & $4[20.0 \%]$ & $8[40.0 \%]$ & $3[15.0 \%]$ & \multirow[t]{2}{*}{6.19} & \multirow[t]{2}{*}{0.11} \\
\hline & Opaque & $11[55.0 \%]$ & $16[80.0 \%]$ & $12[60.0 \%]$ & $17[85.0 \%]$ & & \\
\hline \multicolumn{2}{|l|}{ Stone No.ł } & $2.6 \pm 1.7$ & $2.2 \pm 1.9$ & $2.15 \pm 1.84$ & $\begin{array}{c}1.8 \pm 1.5 ; 1.0- \\
5.0\end{array}$ & 0.62 & 0.603 \\
\hline \multicolumn{2}{|l|}{ Stone SA§ } & $597 \pm 214$ & $442.2 \pm 100.7$ & $484.23 \pm 117.4$ & $348.9 \pm 87.6$ & 11.01 & $<0.001^{*}$ \\
\hline \multicolumn{2}{|l|}{ Stone length } & $43.9 \pm 16.0$ & $36.4 \pm 12.8$ & $41.6 \pm 9.6$ & $28.9 \pm 7.6$ & 6.18 & $0.001^{*}$ \\
\hline
\end{tabular}

† BMl; Body Mass Index; $\ddagger$ No.; Number; § SA; Surface Area.

Table [2]: Operative and Postoperative Data according to Patients' Groups

\begin{tabular}{|c|c|c|c|c|c|c|c|}
\hline \multicolumn{2}{|l|}{ Variable } & First 20 & Second 20 & Third 20 & Fourth 20 & \multirow{3}{*}{$\begin{array}{c}\mathrm{F} \\
5.49\end{array}$} & \multirow{3}{*}{$\begin{array}{c}P \\
0.13\end{array}$} \\
\hline \multirow[t]{2}{*}{ Puncture No.† } & Single & $3[15 \%]$ & $4[20 \%]$ & - & $5[25 \%]$ & & \\
\hline & Multiple & $17[85 \%]$ & $16[80 \%]$ & $20[100 \%]$ & $15[75 \%]$ & & \\
\hline \multicolumn{2}{|l|}{ Irrigating fluid volume } & $30.5 \pm 2.8$ & $14.5 \pm 6.8$ & $9.85 \pm 1.57$ & $9.1 \pm 1.4$ & 135.95 & $<0.001^{*}$ \\
\hline \multicolumn{2}{|l|}{ Operative time } & $117.1 \pm 14.6$ & $91.9 \pm 17.5$ & $79.4 \pm 13.4$ & $60.5 \pm 13.8$ & 50.76 & $<0.001^{*}$ \\
\hline \multicolumn{2}{|c|}{ Reduction in HB $\ddagger$ concentration } & $2.84 \pm 0.63$ & $1.9 \pm 0.6$ & $1.10 \pm 0.15$ & $0.97 \pm 0.13$ & 79.77 & $<0.001^{*}$ \\
\hline \multicolumn{2}{|l|}{ Fluoroscopy time } & $3.60 \pm 0.70$ & $2.5 \pm 0.5$ & $1.78 \pm 0.62$ & $1.48 \pm 0.60$ & 48.03 & $<0.001^{*}$ \\
\hline \multirow{2}{*}{$\begin{array}{l}\text { Stone Clearance } \\
\text { Rate }\end{array}$} & Stone free + CIRF $\S<5 \mathrm{~mm}$ & $7[35.0 \%]$ & $10[50.0 \%]$ & $12[60.0 \%]$ & $16[80.0 \%]$ & \multirow[t]{2}{*}{8.68} & \multirow[t]{2}{*}{$0.034^{*}$} \\
\hline & Residual stone $\geq 5 \mathrm{~mm}$ & $13[65.0 \%]$ & $10[50.0 \%]$ & $8[40.0 \%]$ & $4[20.0 \%]$ & & \\
\hline \multicolumn{2}{|c|}{ PO ¥ rise in serum creatinine } & $11[55.0 \%]$ & $4[20.0 \%]$ & $4[20.0 \%]$ & $3[15.0 \%]$ & 10.28 & $0.016^{*}$ \\
\hline \multicolumn{2}{|l|}{ Urine leak } & $8[40.0 \%]$ & $3[15.0 \%]$ & $2[10.0 \%]$ & $2[10.0 \%]$ & 8.12 & $0.040^{*}$ \\
\hline \multicolumn{2}{|l|}{ Delayed hemorrhage } & $4[20.0 \%]$ & $1[5.0 \%]$ & $0[0.0 \%]$ & $0[0.0 \%]$ & 9.17 & $0.027^{*}$ \\
\hline \multicolumn{2}{|c|}{ Need for blood transfusion } & $12[60.0 \%]$ & $3[15.0 \%]$ & $0[0.0 \%]$ & $0[0.0 \%]$ & 31.75 & $<0.001^{*}$ \\
\hline \multirow[t]{4}{*}{ Fever and/or sepsis } & No & $7[35.0 \%]$ & $16[80.0 \%]$ & $12[60.0 \%]$ & $16[80.0 \%]$ & \multirow[t]{4}{*}{30.40} & \multirow[t]{4}{*}{$<0.001^{*}$} \\
\hline & SIRS£ & $11[55.0 \%]$ & $3[15.0 \%]$ & $4[20.0 \%]$ & $0[0.0 \%]$ & & \\
\hline & Simple fever & $0[0.0 \%]$ & $1[5.0 \%]$ & $0[0.0 \%]$ & $4[20.0 \%]$ & & \\
\hline & MODS $€$ & $2[10.0 \%]$ & $0[0.0 \%]$ & $0[0.0 \%]$ & $0[0.0 \%]$ & & \\
\hline \multirow{5}{*}{$\begin{array}{ll}\text { Grading } & \text { of } \\
\text { Complications }\end{array}$} & None & $0[0.0 \%]$ & $10[50.0 \%]$ & $5[25.0 \%]$ & $12[60.0 \%]$ & \multirow{5}{*}{61.68} & \multirow{5}{*}{$<0.001^{*}$} \\
\hline & $\mathrm{I}$ & $0[0.0 \%]$ & $1[5.0 \%]$ & $11[55.0 \%]$ & $6[30.0 \%]$ & & \\
\hline & II & $15[75 \%]$ & $5[25.0 \%]$ & $4[20.0 \%]$ & $1[5.0 \%]$ & & \\
\hline & $3 a$ & $2[10.0 \%]$ & $4[20.0 \%]$ & $0[0.0 \%]$ & $1[5.0 \%]$ & & \\
\hline & $4 b$ & $3[15.0 \%]$ & $0[0.0 \%]$ & $0[0.0 \%]$ & $0[0.0 \%]$ & & \\
\hline \multicolumn{2}{|l|}{ Hospital stay [days] } & $\begin{array}{l}5.9 \pm 1.2 \\
4.0 \pm 8.0\end{array}$ & $\begin{array}{l}3.9 \pm 1.0 \\
3.0-6.0\end{array}$ & $\begin{array}{c}2.95 \pm 0.76 \\
2.0-5.0\end{array}$ & $\begin{array}{c}2.40 \pm 0.50 \\
2.0-3.0\end{array}$ & 59.34 & $<0.001^{*}$ \\
\hline
\end{tabular}

† No.; Number; $\ddagger$ HB; Hemoglobin; § CIRF; Clinically Insignificant Residual Fragment; ¥ PO; Postoperative; £ SIRS; Systemic Inflammatory Response Syndrome; $€$ MODS; Multiple Organ Dysfunction Syndrome. 


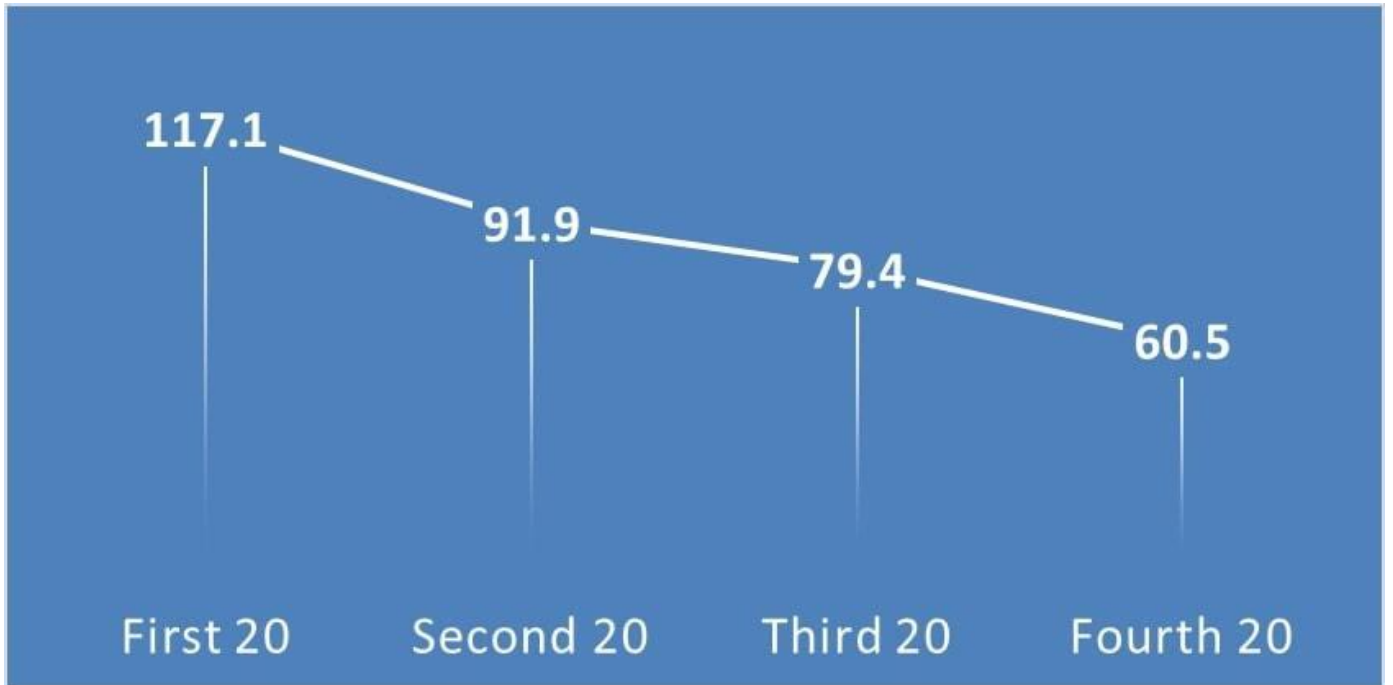

Figure [1] : Line plot curve showing the mean operative time among studied groups.

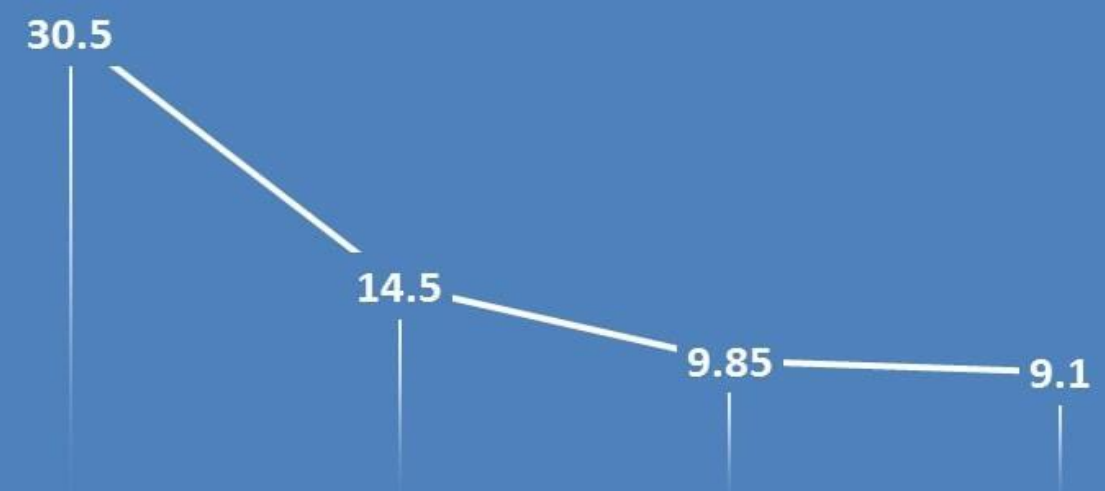
First 20
Second 20
Third 20
Fourth 20

Figure [2]: Line plot curve showing the average volume of irrigation consumed among studied groups.

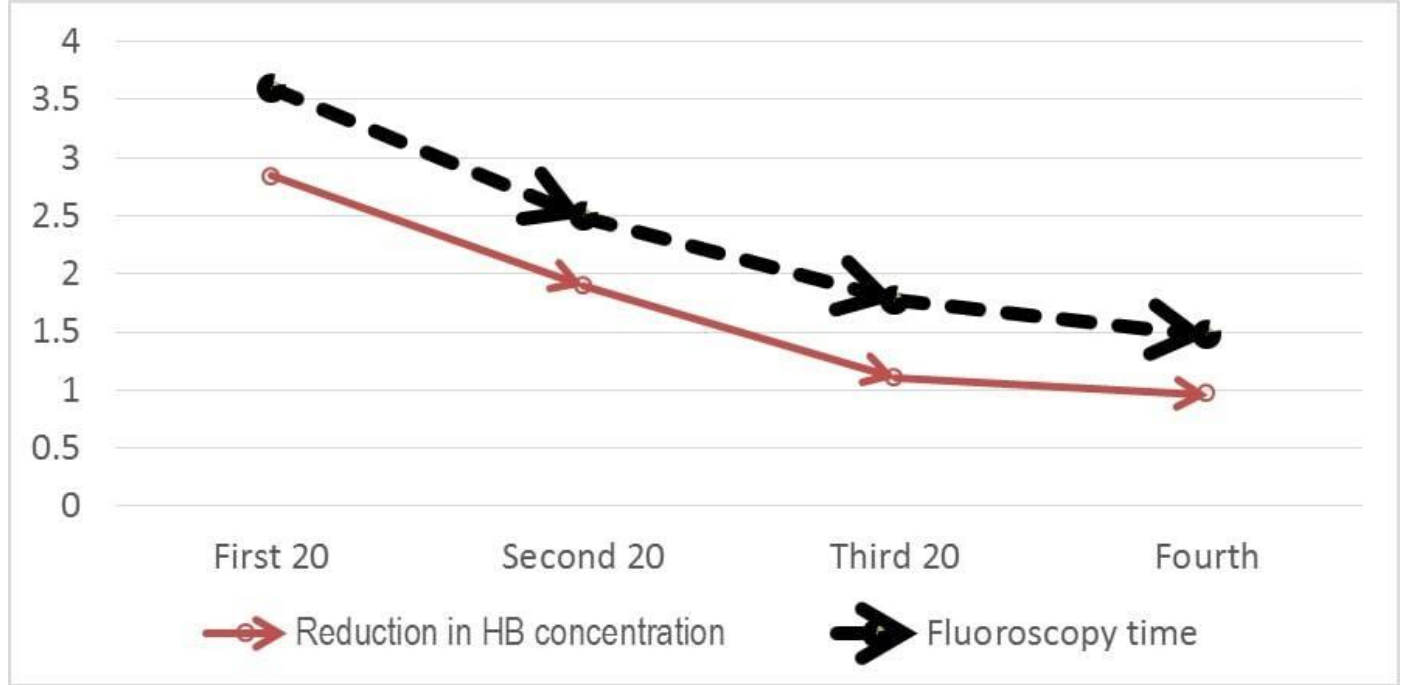

Figure [3]: Line plot curve showing the mean reduction in HB [Hemoglobin] concentration and fluoroscopy screening duration among studied groups. 


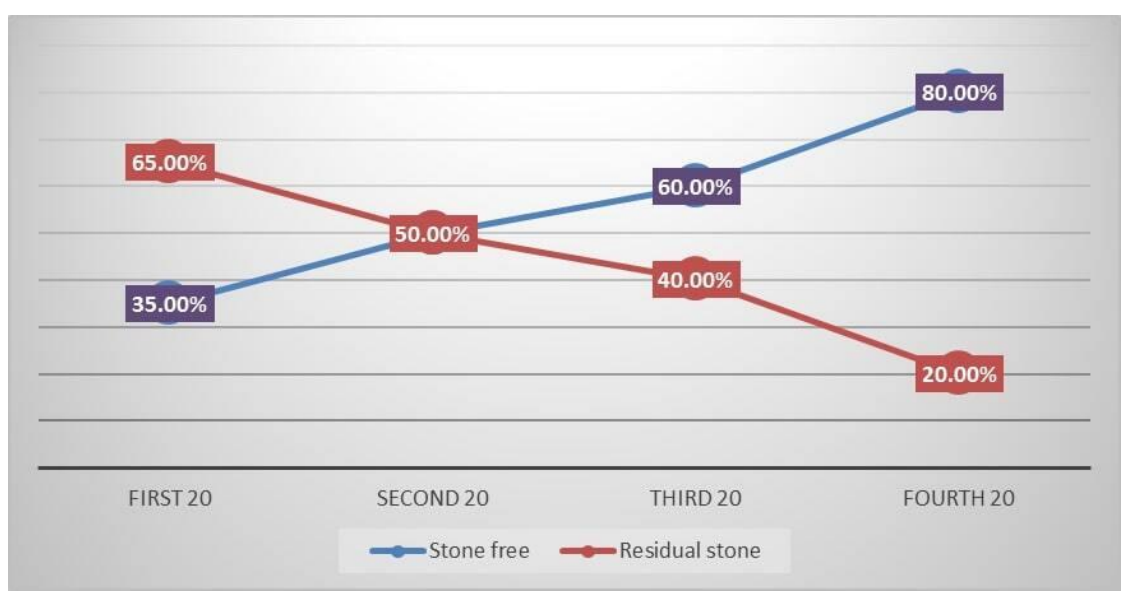

Figure [4]: Line plot curve shows the initial stone-free rate among studied populations.

\section{DISCUSSION}

The concept of the learning curve was introduced by the $19^{\text {th }}$ century German psychologist Heramn Ebbinghaus in his study of the efficiency of his long-term memory to memorize a series of nonsense syllables. Ebbinghaus found that the more he repeated, the more he could remember until finally, he could recall the whole list. He also reported rapid progress in syllable recall during the initial stages, followed by lessening improvements with further practice ${ }^{[16]}$.

If we want to transfer Ebbinghaus' experience to surgery, the "learning curve" can be thought of as an improvement in performance over time. This improvement is at its maximum early on in the learning process then tails off over time ${ }^{[8]}$. In other words, it is the number of procedures needed to gain the surgical competence in performing it. So, if we want to figure out the "learning curve" for a surgical procedure, we first have to preset some relevant clinical endpoints then draw a curve based on surgeon performance against surgical outcome data ${ }^{[0,11]}[9]$, and the point at which the slope reaches a plateau, is the point of competence or learning ${ }^{[17]}$

Since PCNL is a milestone technique in treating upper urinary tract stones, this induced the motivation of urologists to learn this

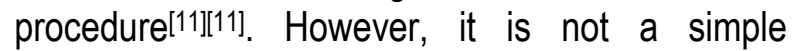
procedure to learn and has a specific set of complications higher than other endoscopic procedures intended for managing stones, which make it, to some extent, a stressful approach, particularly in less experienced hands ${ }^{[18]}$.

To alleviate the anxiety of a surgeon newly performing PCNL, a specific training program has to be settled, that is to define the "learning curve" and provide enough operations for training. From the studies published in the literature on this topic, one may conclude that for an endourologist newly performing PCNL, it is estimated that 45-60 PCNL procedures performed solo are necessary to achieve competence; that is, the learning curve reaches a plateau[9-11,19-21] [9] and $>100$ procedures to excel the procedure $[10,11,22][11]$

Because supine PCNL has proved that it is a good alternative to conventional prone one with comparable efficacy, safety, and feasibility [6,23-25], we have tried in this work to provide an insight into the learning curve of a single surgeon, competent in doing PCNL in the conventional prone position, during his transition to supine one using the following clinical endpoints: economic efficiency (operation and fluoroscopic screening times, the volume of the irrigant fluid consumed and postoperative length of hospital stay), effectiveness (stone clearance rate), and procedure-related morbidity (reduction in hemoglobin concentration, blood transfusion, and complication rates), as measures of outcome.

Reduction of the operation and fluoroscopic screening durations reflect the surgeon's growing familiarity with the procedure, tools, understanding of the endourologic anatomy, and the more rapid 
identification and puncturing the target calyx, and its reduction is an indicator to the ability to perform the procedure[21, 26-27]. In our series, the durations of both showed an observable pattern of progressive decline among groups. The mean operation duration drop from $117 \mathrm{~min}$. in the $1^{\text {st }}$ group to about half (60 minutes) in the $4^{\text {th }}$ group (Figure 1). This is comparable to the results published by Jang et al., who calculated the learning curve for 53 PCNL procedures performed in the flank position by one experienced endourological surgeon. The mean operative time gradually decreased as the surgeon experience increased, and from the $36^{\text {th }}$ case, the mean operative time showed a significant decrease to

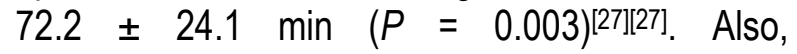
fluoroscopy time declined from 3.5 minutes to 1.5 min. in the last group (Figure 3).

In this study, stone clearance rate has been used as one of the clinical endpoints. It is known that it depends on many factors, including stone (size, number, complexity, composition, and nature), access (type and number), anatomic abnormalities, and technical issues (including the experience of both the operating and supervising surgeons) ${ }^{[10,28]}$.

As depicted in figure 4, our stone clearance rate (stone-free+CIRF $<5 \mathrm{~mm}$ ) continued to improve among groups with more practice $(P=$ $0.034)$, and the slope of the curve was progressing till the end of the study without approaching the plateau. So, if we consider the stone clearance rate as a measure of gaining competence, as stated before by de la Rosette et al.[11] [11]a surgeon needs a higher number of procedures to approach this target, up to the $105^{\text {th }}$ operation.

These results are not in accordance to those published by Tanriverdi et al. and Song et al. that did not show significant changes in sequential groups of patients regarding the stone clearance rate. They concluded that a surgeon could meet this goal very soon after completing the first few procedures ${ }^{[0,21]}$.

Complications were observed among all groups. Most of them were of low grade (Clavien 1 \& 2). The most commonly observed were fever, bleeding requiring blood transfusion, the post- operative rise of serum creatinine, and urinary leakage. Blood loss is a normal feature of PCNL. It is considered a complication only when a blood transfusion is required[29].

In our study, the need for transfusion was significantly higher in the first group (12/20 patients $-60 \%)$. It declined significantly in the $2^{\text {nd }}$ group (3/20 patients $-15 \%)$ to reach $0 \%$ in the 3 rd and $4^{\text {th }}$ groups. Generally speaking, the rate and grade of complications decreased significantly over time as the surgeon accumulated experience and refined the technique. The number of complicated cases in the $4^{\text {th }}$ group was 8 , sex of them was Clavien grade 1 . Where in the first group, all patients, to some extent, were complicated (Table 2). Besides the unfamiliarity with the technique, this higher incidence of complications among the first group can also be attributed to the higher stone burden and complexity when compared to other groups (Table 1).

It is known that the length of hospital stay post-operatively is significantly related with the post-operative occurrence of complications [30][30].

As the rate and grade of complications decreased among groups, the hospital stay duration significantly improved with improvement in the learning curve; the stay duration continued to decrease among groups from ( $5.9 \pm 1.2$ days) in the first group to ( $2.40 \pm 0.50$ days) in the fourth group.

Given the changes in the slope of fluoroscopic screening time, the volume of the irrigant fluid consumed during surgery, the improvement in rate and grade of complications (including transfusion rate), and postoperative length of hospital stay from the third group on; we can conclude that for an endourologist capable of doing PCNL in the conventional prone position, would be able to acquire competency after 40 supine procedures, whatever the complexity of stone is. However, if we consider the operation time and stone clearance rate as measures of achieving competence, given that the slope of the curve was progressing till the end of the study without approaching the plateau, a surgeon needs a higher number of procedures to approach this target. 
The main strength of the current work is that it tracked the number of procedures required to reach an acceptable learning level, when the surgeon's shifted from prone to the supine position. However, it had some limitations. First: this study reflects the learning curve of a single surgeon. So, the interpersonal variations among learning curves of different surgeons based on their skills and expertise have to be kept in mind[17,19]. Second: the study was conducted prospectively in chronological order; this result in an unequal distribution of the stones (regarding its burden and complexity) among different patients' groups, which might be, to some extent, affected the outcome results.

Conclusion: Considering the fluoroscopy duration, the volume of the irrigant fluid consumed, the rate and grade of complications, and the length of hospital stay post-operatively, a surgeon competent in doing PCNL in the conventional prone position can gain competence in doing supine one after 40 procedures regardless the grade of stone complexity. Improvement in operative time and stone clearance rate continued till the end of our study; that is, a surgeon needs a higher number of procedures for his learning curve to reaches a plateau.

\section{Financial and Non-Financial Relationships and Activities of Interest}

\section{None}

\section{References}

1. Fernström I, Johansson B. Percutaneous pyelolithotomy. A new extraction technique. Scand $\mathrm{J}$ Urol Nephrol 1976; 10: 257-259. DOI: 10.1080/21681805. 1976.11882084

2. Alken $P$, Hutschenreiter $G$, Gunther $R$, Marberger $M$. Percutaneous stone manipulation. J Urol. 1981; 125 : 463-466. DOI: 10.1016/s0022-5347[17]55073-9

3. Atkinson CJ, Turney BW, Noble JG, Reynard JM, Stoneham MD. Supine vs prone percutaneous nephrolithotomy: an anesthetist's view. BJU Int 2011; 108: 306-8. DOI: 10.1111/j.1464-410X.2011.10488.x

4. Cracco CM, Alken P, Scoffone CM. Positioning for percutaneous nephrolithotomy. Curr. Opin. Urol. 2016; 26: 81-87. DOI: 10.1097/MOU.0000000000000239

5. Valdivia Uria JG, Valle Gerhold J, Lopez Lopez JA. Why Is Percutaneous Nephroscopy Still Performed with the Patient Prone? J Endourol 1990; 4[3]: 269-277. http://doi.org/10.1089/end.1990.4.269

6. Mak DK, Smith Y, Buchholz N, El-Husseiny T. What is better in percutaneous nephrolithotomy - Prone or supine? A systematic review. Arab J Urol. 2016; 14[2]: 101-7. DOI: 10.1016/j.aju.2016.01.005

7. Türk C, Knoll T, Petrik A, El-Husseiny T. Guidelines on urolithiasis. Available from: http://www.uroweb. org/gls/ pdf/ 20_Urolithiasis_LR\%20Marc h\%2013\%202012.pdf. Accessed May 15, 2012

8. Hamid Abboudi, Mohammed Shamim Khan, Khurshid A. Guru, Saied Froghi, Gunter de Win, Hendrik Van Poppel, et al. Learning curves for urological procedures: a systematic review. BJU Int 2014; 114: 617-629. DOI: 10.1111/bju. 12315

9. Tanriverdi O, Boylu U, Kendirci M, Kadihasanoglu M, Horasanli K, Miroglu C. The learning curve in the training of percutaneous nephrolithotomy. Eur Urol. 2007; 52: 206-11. DOI: 10.1016/j.eururo.2007.01.001

10. Allen $D, O$ 'Brien $T$, Tiptaft $R$, Glass J. Defining the learning curve for percutaneous nephrolithotomy. J Endourol 2005; 19: 279-82. DOI: 10.1089/end.2005.19. 279

11. de la Rosette JJ, Laguna MP, Rassweiler JJ, Conort P. Training in percutaneous nephrolithotomy -- a critical review. Eur Urol. 2008; 54: 994-1001. DOI: 10.1016/ j.eururo.2008.03.052

12. Tiselius HG, Andersson A. Stone burden in an average Swedish population of stone formers requiring active stone removal: how can the stone size be estimated in the clinical routine? Eur Urol. 2003; 4: 275-81. DOI: 10. 1016/s0302-2838[03]00006-x

13. Thomas K, Smith NC, Hegarty N, Glass JM. The Guy's stone score--grading the complexity of percutaneous nephrolithotomy procedures. Urology 2011; 78 [2]: 27781. DOI: 10.1016/j.urology.2010.12.026

14. Clavien PA, Barkun J, de Oliveira ML, Vauthey JN, Dindo D, Schulick RD et al. The Clavien-Dindo Classification of surgical complications. Five-year experience. Ann Surg 2009; 250: 187-196. DOI: 10.1097/ SLA.0b013e3181b13ca2

15. de la Rosette JJ, Opondo D, Daels FP, Giusti G, Serrano A, Kandasami SV, et al. Categorization of complications and validation of the Clavien score for percutaneous nephrolithotomy. Eur Urol. 2012; 62: 246--55. DOI: 10.1016/j.eururo.2012.03.055

16. Ebbinghaus H., Ruger HA [Trans], Bussenius CE [Trans]. Ebbinghaus, H. Memory: A Contribution to Experimental Psychology. NY: Columbia University Teacher's College Press, 1913. DOI:10.1037/10011-000. Quoted from Louis Alfieri, Timothy J. Nokes-Malach \& Christian D. Schunn (2013): Learning Through Case 
Comparisons: A Meta-Analytic Review, Educational Psychologist, 48:2, 87-113. DOI: 10.1080/ 00461520. 2013.775712

17. Breda A. Editorial comment on: training in percutaneous nephrolithotomy-a critical review. Eur Urol. 2008; 54: 1001-2. DOI: 10.1016/j.eururo.2008.03.053

18. Michel MS, Trojan L, Rassweiler JJ. Complications in percutaneous nephrolithotomy. Eur Urol 2007; 51: 899_ 906. DOI: 10.1016/j.eururo.2006.10.020

19. Seyed Amir Mohsen Ziaee, Mehrdad Mohammadi Sichani, Amir Hossein Kashi, Mohammad Samzadeh. Evaluation of the Learning Curve for Percutaneous Nephrolithotomy. Urol J. 2010; 7: 226-31. DOI: 10. 22037/uj.v7i4.818

20. Schilling D, Gakis G, Walcher U, Stenzl A, Nagele U. The learning curve in minimally invasive percutaneous nephrolitholapaxy: a 1-year retrospective evaluation of a novice and an expert. World J Urol. 2011; 29[6]: 749753. DOI: $10.1007 / \mathrm{s} 00345-010-0553-3$

21. Song $Y$, Ma $Y$, Song $Y$, Fei $X$. Evaluating the Learning Curve for Percutaneous Nephrolithotomy under Total Ultrasound Guidance. PLoS ONE 2015; 10[8]: e0132986. DOI: 10.1371/journal.pone.0132986

22. Chi-Fai Ng. Training in percutaneous nephrolithotomy: The learning curve and options. Arab J Urol 2014; 12 : 54-57. DOI: 10.1016/j.aju.2013.08.002

23. Falahatkar S, Moghaddam AA, Salehi M, Nikpour S, Esmaili F, Khaki N. Complete supine percutaneous nephrolithotripsy comparison with the prone standard technique. J Endourol 2008; 22: 2513-7. DOI: 10.1089/ end.2008.0463
24. Youssef $\mathbf{A}$, Esmat $\mathbf{M}$, Wael $\mathbf{M}$. When prone position is contraindicated or not preferable, can supine percutaneous nephrolithotomy solve the problem? Int Braz J Urol 2012; 38: 57-62. DOI: 10.1590/\$167755382012000100008

25. Nadeem Sohail, Amjad Albodour, Khalid Mohammed Abdelrahman. Percutaneous nephrolithotomy in complete supine flank-free position in comparison to prone position: A single-centre experience. Arab Journal of Urology 2017; 15: 42-47. DOI: 10.1016/j.aju.2016.10. 001

26. Breda A. Editorial comment on: The learning curve in the training of percutaneous nephrolithotomy. Eur Urol. 2007; 52: 211-2. DOI: 10.1016/j.eururo.2007.01.002

27. Jang W, Choi K, Yang S, Han W. The Learning Curve for Flank Percutaneous Nephrolithotomy for Kidney Calculi: A Single Surgeon's Experience. Korean journal of urology 2011; 52: 284-8. DOI: 10.4111/kju.2011.52. 4.284

28. Skolarikos A, Alivizatos G, de la Rosette JJ. Percutaneous nephrolithotomy and its legacy. Eur Urol. 2005; 47: 22-8. DOI: 10.1016/j.eururo.2004.08.009

29. El-Nahas A, Shokeir A, El-Assmy A, Mohsen T., Shoma A., Eraky I., et al. Post percutaneous nephrolithotomy extensive hemorrhage: A study of risk factors. J Urol. 2007; 177[2]:576-9. DOI: 10.1016/j.juro. 2006.09.048

30. Vorrakitpokatorn P, Permtongchuchai K, Raksamani EO, Phettongkam A. Perioperative complications and risk factors of percutaneous nephrolithotomy. J Med Assoc Thai. Jun 2006; 89[6]: 826-33. PMID: 16850684. 


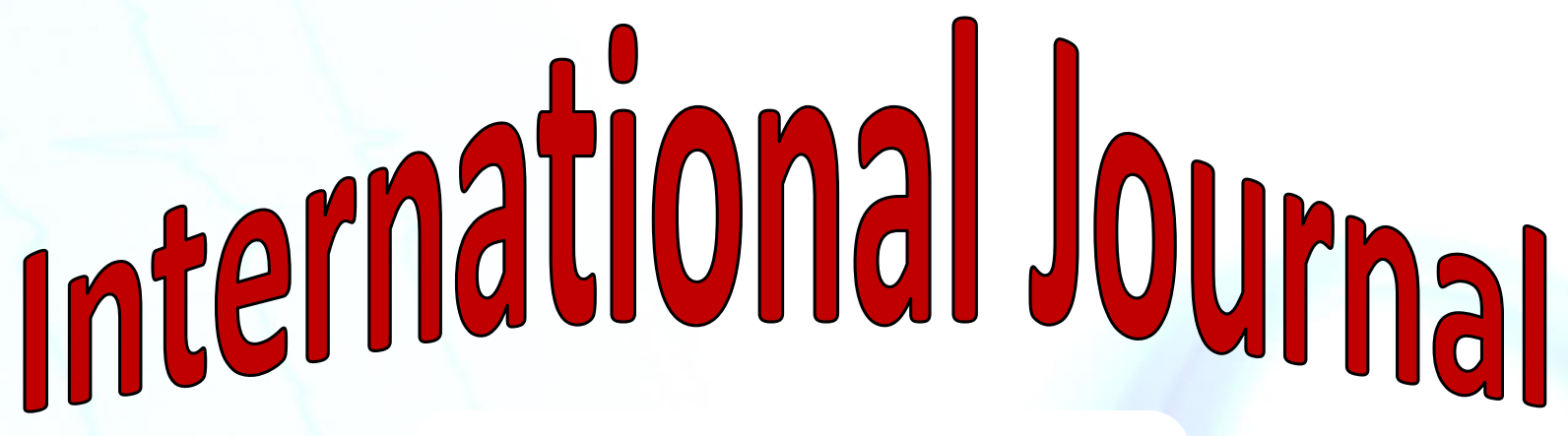

https://ijma.journals.ekb.eg/

Print ISSN: 2636-4174

Online ISSN: 2682-3780

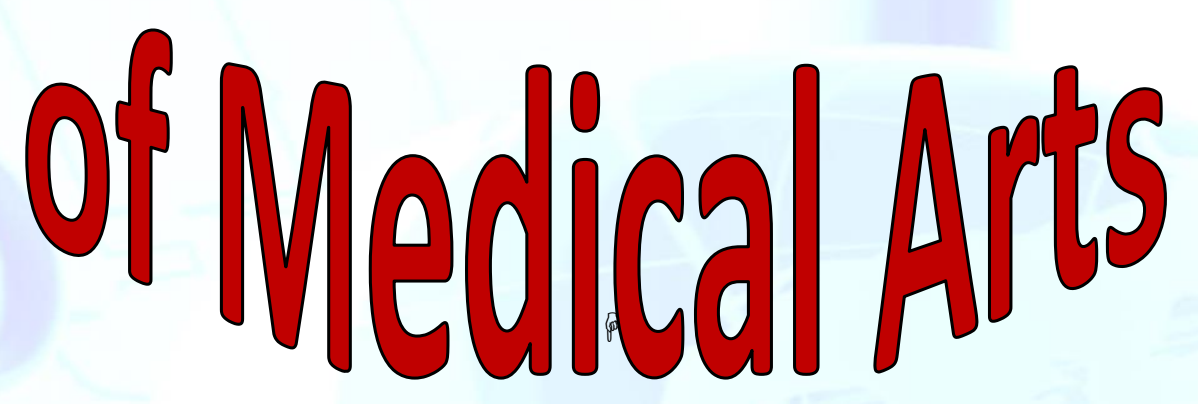

